\title{
The Therapeutic Potential of Carbon Monoxide for Inflammatory Bowel Disease
}

\author{
Tomohisa Takagi Kazuhiko Uchiyama Yuji Naito \\ Molecular Gastroenterology and Hepatology, Graduate School of Medical Science, Kyoto Prefectural University \\ of Medicine, Kyoto, Japan
}

\section{Key Words}

Carbon monoxide $\cdot$ Heme oxygenase $\cdot$ Inflammatory bowel disease $\cdot$ Ulcerative colitis $\cdot$ Crohn's disease

\begin{abstract}
Inflammatory bowel disease (IBD), encompassing ulcerative colitis and Crohn's disease, are chronic, relapsing and remitting inflammatory disorders of the intestinal tract. Because the precise pathogenesis of IBD remains unclear, it is important to investigate the pathogenesis of IBD and to evaluate new anti-inflammatory strategies. Recent accumulating evidence has suggested that carbon monoxide (CO) may act as an endogenous defensive gaseous molecule to reduce inflammation and tissue injury in various organ injury models, including intestinal inflammation. Furthermore, exogenous $\mathrm{CO}$ administration at low concentrations is protective against intestinal inflammation. These data suggest that CO may be a novel therapeutic molecule in patients with IBD. In this review, we present what is currently known regarding the therapeutic potential of $\mathrm{CO}$ in intestinal inflammation.
\end{abstract}

(c) 2015 S. Karger AG, Basel
(C) 2015 S. Karger AG, Basel

0012-2823/15/0911-0013\$39.50/0

\section{Introduction}

Inflammatory bowel disease (IBD), encompassing ulcerative colitis (UC) and Crohn's disease (CD), is a chronic, relapsing and remitting inflammatory disorder of the intestinal tract. The incidence of IBD is rapidly increasing in eastern countries, including Japan, as well as in North America and Europe [1]. Although the cause of IBD has been extensively investigated over the last few decades, the pathogenesis of IBD is not fully elucidated. Recent research has suggested that a complex interplay between the host genotypes, the immune system and intestinal microbiota plays a crucial role in understanding IBD pathogenesis [2]. At present, the major challenges in the management of IBD include the rapid induction of remission and the prevention of relapse. Medical management, such as the administration of 5-aminosalicylic acid, corticosteroids, immunosuppressive agents and biologic agents, such as anti-tumor necrosis factor (TNF)- $\alpha$ agents, of patients with acute exacerbations of IBD focuses on achieving remission by inhibiting intestinal inflammation and repairing mucosal injury [3]. However, some patients

\section{KARGER 125}

E-Mail karger@karger.com www.karger.com/dig
Tomohisa Takagi, MD, PhD

Molecular Gastroenterology and Hepatology, Graduate School of Medical Science Kyoto Prefectural University of Medicine

465 Kajii-cho, Kawaramachi-Hirokoji, Kamigyo-ku, Kyoto 602-8566 (Japan)

E-Mail takatomo@koto.kpu-m.ac.jp 
with IBD do not respond or respond incompletely to these treatments. Therefore, it is important to investigate new anti-inflammatory strategies.

Carbon monoxide (CO), which is an invisible, colorless and odorless gas, is a major product of the incomplete combustion of carbon and carbon-containing compounds. $\mathrm{CO}$ is widely known to be a toxic gas because $\mathrm{CO}$ avidly binds to hemoglobin with a higher affinity than oxygen and forms carboxyhemoglobin, resulting in interference with the oxygen-carrying capacity of the blood and consequent tissue hypoxia. However, it is well known that $\mathrm{CO}$ is endogenously produced. Endogenous $\mathrm{CO}$ is one of the three products of heme degradation by heme oxygenase (HO), with the other two being $\mathrm{Fe}^{2+}$ and biliverdin $[4,5]$.

Recently, the inducible form of $\mathrm{HO}, \mathrm{HO}-1$, has been shown to exert potent cellular protective effects due to its anti-inflammatory, antiapoptotic and antioxidant actions in various settings [6]. Regarding intestinal inflammation, our previous report has shown that HO-1 mRNA and protein are overexpressed in mainly infiltrative inflammatory cells in the intestinal mucosa of patients with active UC, and this upregulated HO-1 might lead to an anti-inflammatory effect [7]. Wang et al. [8] have reported that $\mathrm{HO}$ expression increases considerably in rat 2,4,6-trinitrobenzene sulfonic acid (TNBS)-induced colitis, which is a well-accepted model of IBD. The authors demonstrated that the inhibition of HO-1 activity exacerbates experimental colitis, indicating that $\mathrm{HO}-1$ plays an important protective role in intestinal inflammation. We have also described the importance of $\mathrm{HO}-1$ in intestinal inflammation by focusing on the BTB and CNC homolog 1 (Bach1), which is a transcriptional repressor of $\mathrm{HO}-1$. Bach1-deficient mice exhibit dramatic increases in $\mathrm{HO}-1$ expression in the gastrointestinal tract, and TNBSinduced colonic inflammation is remarkably attenuated in Bach1-deficient mice, indicating that HO-1 has an important anti-inflammatory function in intestinal inflammation $[9,10]$.

Although the beneficial roles of HO-1 are not completely understood, these cytoprotective and anti-inflammatory effects of HO-1 are related to the formation of its end product. The pharmacological application of $\mathrm{CO}$ can especially mimic the HO-1-dependent cytoprotection and anti-inflammatory effects in many injury models, including colitis models [11]. Hence, CO might be a novel and important molecule in the treatment of intestinal inflammation [12]. This article provides a short overview of the recent advances concerning the therapeutic potential of CO for intestinal inflammation.

\section{Molecular Mechanism of CO Action}

As mentioned above, in addition to the inhalation of exogenous gas, a significant amount of $\mathrm{CO}$ is endogenously and physiologically produced in mammalian cells through heme degradation in a rate-limiting step by microsomal $\mathrm{HO}[4,5]$. For $\mathrm{CO}$ action, it is critical for $\mathrm{CO}$ to bind the heme moiety and activate heme-containing proteins, such as hemoglobin, myoglobin, cytochrome c [13], cytochrome P450 (CYP) [14], soluble guanylate cyclase (sGC) [15], catalase, NADPH oxidase and the transcription factor neuronal PAS domain protein 2 [16]. The interactions of $\mathrm{CO}$ with heme-containing proteins underlie various cellular events that are conducted through the production of mitochondrial reactive oxygen species, such as the promotion of autophagy [17], the inhibition of cytochrome $c$ oxidase leading to a decreased reactive oxygen species generation [18], and the triggering of adaptive responses and cell survival.

The breakdown of CYP, which constitutes a large group of heme proteins, is induced during organ injury by various insults. It has been reported that $\mathrm{CO}$ in the organ preservation solution that is used during kidney transplantation can bind to and stabilize renal CYP and prevent CYP degradation and detrimental heme release in renal grafts [19]. In addition, it has been reported that CO-bound red blood cells reduce hepatic ischemia-reperfusion (I-R) injury through the inhibition of CYP destruction [20].

Although $\mathrm{CO}$ is a weak activator of sGC in vitro, with a much lower potency and efficacy than $\mathrm{NO}$, endogenous $\mathrm{CO}$ is also known to bind and activate sGC [15]. The treatment of different tissues with $\mathrm{CO}$ increases cyclic guanosine monophosphate (cGMP) production, the activation of type-I cGMP-dependent protein kinase, and smooth muscle relaxation [5], suggesting that in vivo CO modulates cGMP levels. The activation of cGMP-dependent protein kinase I is one of the targets of $\mathrm{CO}$, resulting in smooth muscle relaxation through direct effects on the contractile machinery as well as by altering $\mathrm{Ca}^{2+}$ homeostasis and voltage-gated ion channel activity [21]. CO has also been reported to activate $\mathrm{K}^{+}$channels in a variety of tissues [22], including the gastrointestinal tract, because intracellular cGMP activates $\mathrm{K}^{+}$channels and cGMP levels are increased by treatments with exogenous CO [23].

The antiapoptotic effects of $\mathrm{CO}$ have been reported in in vitro models of TNF- $\alpha$-initiated apoptosis. For example, Brouard et al. [24] have shown that TNF- $\alpha$-initiated apoptosis is inhibited by $\mathrm{CO}$ in mouse endothelial cells through the activation of the $\mathrm{p} 38$ MAPK pathway. Fur- 
Table 1. Therapeutic application of $\mathrm{CO}$ in intestinal inflammation using in vivo animal colitis models

\begin{tabular}{llll}
\hline Type of experimental models & Application of CO & Animal & First author [ref.], year \\
\hline DSS-induced colitis & CO inhalation $(250 \mathrm{ppm})$ & Joe [47], 2014 \\
DSS-induced colitis & CO-releasing molecule (CORM-2) & mouse & Uddin [48], 2013 \\
DSS-induced colitis & CO-releasing molecule (CORM-3) & mouse & Fukuda [45], 2014 \\
IL-10-deficient (genetic colitis model) & CO-releasing molecule (ALF186) & mouse & Onyiah [49], 2013 \\
TNBS-induced colitis & CO colonic insufflation (200 ppm) & rat & Takagi [51], 2012 \\
TCR- $a$-deficient (genetic colitis model) & CO inhalation (250 ppm) & mouse & Sheikh [40], 2011 \\
DSS-induced colitis & CO-releasing molecule (CORM-2) & mouse & Takagi [46], 2011 \\
TNBS-induced colitis & CO inhalation $(200 \mathrm{ppm})$ & mouse & Takagi [41], 2010 \\
IL-10-deficient (genetic colitis model) & CO inhalation $(250 \mathrm{ppm})$ & mouse & Hegazi [39], 2005 \\
Necrotizing enterocolitis & CO inhalation $(250 \mathrm{ppm})$ & rat & Zuckerbraun [42], 2005 \\
\hline
\end{tabular}

thermore, $\mathrm{HO}$-1-derived $\mathrm{CO}$ induced NF- $\mathrm{kB}$-dependent antiapoptotic genes to protect against TNF- $\alpha$-mediated endothelial cell apoptosis [25]. Low-dose pretreatment with $\mathrm{CO}$ has been reported to show antiapoptotic effects in several models of disease and tissue injury. Exogenously applied CO inhibited the I-R-induced apoptosis that is associated with the CO-dependent activation of p38 MAPK and the upstream MAPK kinase, and with the suppression of ERK and JNK activation [26]. Recently, $\mathrm{CO}$ has been found to inhibit cellular apoptosis through the direct prevention of mitochondrial membrane permeabilization $[27,28]$.

Anti-inflammatory effects of $\mathrm{CO}$ have been observed in cell cultures and animal models of sepsis [29, 30]. TNF- $\alpha$ expression after treatment with lipopolysaccharide is inhibited by $\mathrm{CO}$ administration or $\mathrm{HO}-1$ overexpression in RAW264.7 cells. The mechanisms by which $\mathrm{CO}$ treatment inhibits the lipopolysaccharide-induced activation of NF- $\kappa \mathrm{B}$ have been found to occur by preventing the phosphorylation and degradation of the inhibitory subunit I- $\kappa \mathrm{Ba}$, and this mechanism has been associated with granulocyte macrophage colony-stimulating factor (GM-CSF) modulation [31]. GM-CSF is a glycoprotein that reportedly enhances the secretion of proinflammatory cytokines, including TNF- $\alpha$, interleukin (IL)- 1 and interferon (IFN)- $\gamma$ [32]. In several inflammatory models, CO has been shown to inhibit GM-CSF expression, resulting in an attenuation of inflammation.

\section{Therapeutic Effects of CO in IBD}

Numerous previous studies have shown that individuals who smoke are more likely to be protected against the development of UC and are less likely to require colecto- mies [33]. In CD, smoking is positively correlated with the development of intestinal inflammation. Interestingly, some studies have established a higher rate of ileal complication and a lower prevalence of colonic complication in CD patients who are smokers [34]. These findings suggest that smoking may provide a protective effect to the large intestine. The detailed mechanisms by which smoking exerts these effects remain unclear, but CO, which is one of the components of cigarette smoke, reportedly ameliorates intestinal inflammation. Therefore, $\mathrm{CO}$ may be a potent therapeutic molecule in intestinal inflammation.

Potent therapeutic efficacies of $\mathrm{CO}$ have been demonstrated in experimental models of several conditions, including lung injuries [35], heart, hepatic and renal I-R injuries $[19,36,37]$, as well as inflammation, including arthritis [38], supporting the new paradigm that $\mathrm{CO}$ at low concentrations functions as a signaling molecule that exerts significant cytoprotection and anti-inflammatory actions. Similar to what has been observed for the therapeutic effects of $\mathrm{CO}$ against various diseases, $\mathrm{CO}$ has been reported to mediate potent cytoprotective and anti-inflammatory effects in in vivo colitis models (table 1).

Hegazi et al. [39] reported that $\mathrm{CO}$ administration ameliorates chronic intestinal inflammation in IL-10-deficient mice, which is a well-established model of spontaneously developing and $\mathrm{T}$ helper 1-mediated colitis. The authors have reported that $\mathrm{CO}$ alters IFN- $\gamma$ signaling in macrophages and decreases IFN regulatory factor- 8 and IL-12 p40 expression. Sheikh et al. [40] have demonstrated that $\mathrm{CO}$ exposure ameliorates chronic T helper 2-mediated colitis in $\mathrm{T}$ cell receptor- $\alpha$-deficient mice and that this CO-mediated amelioration of colitis was associated with increased IL-10 and IL-22 production. We have also reported that $\mathrm{CO}$ inhalation ameliorates TNBS-induced 
colitis in mice [41]. In that study, the macroscopic damage score, thiobarbituric acid-reactive substances, which are used as an index of lipid peroxidation, and tissue-associated myeloperoxidase activity, which is used as an index of neutrophil infiltration in colonic mucosa, were inhibited by CO treatment. Furthermore, the expression of TNF- $\alpha$ in colonic mucosa and TNF- $\alpha$ production by $\mathrm{CD} 4+\mathrm{T}$ cells that were isolated from the spleen were significantly inhibited. Because TNF- $\alpha$ has been reported to play a key role in the pathogenesis of IBD and TNF- $\alpha-$ blocking agents have been used as therapeutic agents for treating IBD worldwide [3], our observation that $\mathrm{CO}$ regulates TNF- $\alpha$ production may fit newer IBD therapeutic strategies. Zuckerbraun et al. [42] have also demonstrated that inhaled CO protected against the development of intestinal inflammation in a model of experimental necrotizing enterocolitis, and that $\mathrm{CO}$ abrogated increased levels of serum TNF- $\alpha$ after the induction of colitis. Thus, CO leads to the inhibition of intestinal inflammation through the regulation of the production of various cytokines.

Recently, transitional metal carbonyls, which are called CO-releasing molecules (CORMs), have been used in biological systems to deliver $\mathrm{CO}$ in a controlled manner while keeping carboxyhemoglobin levels stable [43]. CORM-released $\mathrm{CO}$ has also been found to inhibit various inflammatory states, including intestinal I-R injury [44]. For the effects of CORMs in colitis models, we have described that CORMs inhibited the development of murine dextran sodium sulfate (DSS)- and TNBS-induced colitis through the inhibition of $\mathrm{KC}$ (a functional homolog of human IL8 ) and IL-17A production $[45,46]$. Recent studies using CORMs have suggested another molecular mechanism by which CO exerts the regulation of intestinal inflammation. It has been demonstrated that $\mathrm{CO}$ regulates tristetraprolin, which is an ARE-binding protein that promotes the degradation of a number of inflammatory mediators [47]. In addition, Uddin et al. [48] have demonstrated that CO inhibits glycogen synthase kinase- 3 signaling, which is a constitutively active serine/threonine protein kinase mediating NF- $\kappa \mathrm{B}$ activity. Interestingly, Onyiah et al. [49] have shown that CORM-derived CO ameliorates intestinal inflammation in IL-10-deficient mice in part by augmenting clearance of enteric microbes that breach the epithelial barrier. Furthermore, the authors found that $\mathrm{CO}$ promoted bacterial clearance through the enhancement of the bactericidal activity in macrophages. These data may indicate pleiotropic effects of CO.

The promotion of colonic mucosal healing and the reduction of mucosal inflammation are important therapeutic strategies for controlling the pathogenesis of IBD.
Recently, we have demonstrated that $\mathrm{CO}$ promotes colonic epithelial cell restitution through the activation of colonic submucosal myofibroblasts [50]. In brief, CO induces FGF15 expression in mouse colonic myofibroblasts through the inhibition of miR-710, and FGF15 enhances the restitution of mouse colonic epithelial cells. These findings suggest $\mathrm{CO}$ as a possible therapeutic agent for IBD through its anti-inflammatory effects and colonic mucosal healing.

Regarding the route of $\mathrm{CO}$ application, we have reported that $\mathrm{CO}$ gas insufflation into the colonic lumen inhibits TNBS-induced colitis [51]. Importantly, blood $\mathrm{CO}$ concentrations were not increased after $\mathrm{CO}$ insufflation into the colonic lumen, indicating that the rectal administration of $\mathrm{CO}$ gas might be a safe and realistic route for its clinical application in contrast with the inhalation of CO gas, which was highly toxic due to the high blood CO concentration.

\section{Conclusion}

As highlighted above, $\mathrm{CO}$ has the ability to produce anti-inflammatory and tissue-protective effects. Although further studies are needed to clarify these novel effects of $\mathrm{CO}$ on IBD, CO may have great potential as a new therapeutic molecule for treating IBD.

\section{Acknowledgements}

This work was supported by a Grant-in-Aid for Scientific Research $^{\circledR}$ to Tomohisa Takagi (No. 25460959) from the Japan Society for the Promotion of Science (JSPS).

\section{Disclosure Statement}

Yuji Naito received scholarship funds from Otsuka Pharmaceutical Co. Ltd. and Takeda Pharmaceutical Co. Ltd. The other authors have no conflicts of interest to declare.

References Watanabe M, Takebayashi T: Prevalence of ulcerative colitis and Crohn's disease in Japan. J Gastroenterol 2009;44:659-665.

-2 Xavier RJ, Podolsky DK: Unravelling the pathogenesis of inflammatory bowel disease. Nature 2007;448:427-434.

-3 Blonski W, Buchner AM, Lichtenstein GR: Inflammatory bowel disease therapy: current state-of-the-art. Curr Opin Gastroenterol 2011;27:346-357.
16 
4 Naito Y, Takagi T, Yoshikawa T: Heme oxygenase-1: a new therapeutic target for inflammatory bowel disease. Aliment Pharmacol Ther 2004;20(suppl 1):177-184.

5 Maines MD: The heme oxygenase system: a regulator of second messenger gases. Annu Rev Pharmacol Toxicol 1997;37:517-554.

6 Morse D, Choi AM: Heme oxygenase-1: from bench to bedside. Am J Respir Crit Care Med 2005; 172:660-670.

-7 Takagi T, Naito Y, Mizushima K, Nukigi Y, Okada H, Suzuki T, Hirata I, Omatsu T, Okayama T, Handa O, Kokura S, Ichikawa H, Yoshikawa T: Increased intestinal expression of heme oxygenase-1 and its localization in patients with ulcerative colitis. J Gastroenterol Hepatol 2008;23(suppl 2):S229-S233.

8 Wang WP, Guo X, Koo MW, Wong BC, Lam SK, Ye YN, Cho CH: Protective role of heme oxygenase- 1 on trinitrobenzene sulfonic acid-induced colitis in rats. Am J Physiol Gastrointest Liver Physiol 2001;281:G586-G594.

-9 Harusato A, Naito Y, Takagi T, Uchiyama K, Mizushima K, Hirai Y, Higashimura Y, Katada K, Handa O, Ishikawa T, Yagi N, Kokura $\mathrm{S}$, Ichikawa $\mathrm{H}$, Muto A, Igarashi K, Yoshikawa T: BTB and CNC homolog 1 (bach1) deficiency ameliorates TNBS colitis in mice: role of M2 macrophages and heme oxygenase- 1 . Inflamm Bowel Dis 2013;19:740-753.

10 Higashimura Y, Naito Y, Takagi T, Mizushima K, Hirai Y, Harusato A, Ohnogi H, Yamaji R, Inui H, Nakano Y, Yoshikawa T: Oligosaccharides from agar inhibit murine intestinal inflammation through the induction of heme oxygenase- 1 expression. J Gastroenterol 2013;48:897-909.

-11 Gibbons SJ, Verhulst PJ, Bharucha A, Farrugia G: Review article: carbon monoxide in gastrointestinal physiology and its potential in therapeutics. Aliment Pharmacol Ther 2013;38:689-702.

12 Takagi T, Naito Y, Uchiyama K, Yoshikawa T: The role of heme oxygenase and carbon monoxide in inflammatory bowel disease. Redox Rep 2010;15:193-201.

13 Piantadosi CA, Sylvia AL, Saltzman HA, Jobsis-Vandervliet FF: Carbon monoxide-cytochrome interactions in the brain of the fluorocarbon-perfused rat. J Appl Physiol 1985; 58:665-672.

14 Coceani F, Kelsey L, Seidlitz E: Carbon monoxide-induced relaxation of the ductus arteriosus in the lamb: evidence against the prime role of guanylyl cyclase. Br J Pharmacol 1996; 118:1689-1696.

-15 Kajimura M, Fukuda R, Bateman RM, Yamamoto T, Suematsu M: Interactions of multiple gas-transducing systems: hallmarks and uncertainties of $\mathrm{CO}, \mathrm{NO}$, and $\mathrm{H}_{2} \mathrm{~S}$ gas biology. Antioxid Redox Signal 2010;13:157-192.

16 Dioum EM, Rutter J, Tuckerman JR, Gonzalez G, Gilles-Gonzalez MA, McKnight SL: NPAS2: a gas-responsive transcription factor. Science 2002;298:2385-2387.

17 Lee SJ, Ryter SW, Xu JF, Nakahira K, Kim HP, Choi AM, Kim YS: Carbon monoxide acti- vates autophagy via mitochondrial reactive oxygen species formation. Am J Respir Cell Mol Biol 2011;45:867-873.

-18 Zuckerbraun BS, Chin BY, Bilban M, d'Avila JC, Rao J, Billiar TR, Otterbein LE: Carbon monoxide signals via inhibition of cytochrome $c$ oxidase and generation of mitochondrial reactive oxygen species. FASEB J 2007;21:1099-1106.

19 Nakao A, Faleo G, Shimizu H, Nakahira K, Kohmoto J, Sugimoto R, Choi AM, McCurry KR, Takahashi T, Murase N: Ex vivo carbon monoxide prevents cytochrome p450 degradation and ischemia/reperfusion injury of kidney grafts. Kidney Int 2008;74:1009-1016.

20 Ogaki S, Taguchi K, Watanabe H, Ishima Y, Otagiri M, Maruyama T: Carbon monoxidebound red blood cell resuscitation ameliorates hepatic injury induced by massive hemorrhage and red blood cell resuscitation via hepatic cytochrome 4450 protection in hemorrhagic shock rats. J Pharm Sci 2014;103: 2199-2206.

21 Carvajal JA, Germain AM, Huidobro-Toro JP, Weiner CP: Molecular mechanism of cGMP-mediated smooth muscle relaxation. J Cell Physiol 2000;184:409-420.

22 Wang Z, Yue P, Lin DH, Wang WH: Carbon monoxide stimulates $\mathrm{Ca}^{2+}$-dependent bigconductance $\mathrm{K}$ channels in the cortical collecting duct. Am J Physiol Renal Physiol 2013; 304:F543-F552.

23 Liu H, Mount DB, Nasjletti A, Wang W: Carbon monoxide stimulates the apical 70-pS K ${ }^{+}$ channel of the rat thick ascending limb. J Clin Invest 1999;103:963-970.

-24 Brouard S, Otterbein LE, Anrather J, Tobiasch E, Bach FH, Choi AM, Soares MP: Carbon monoxide generated by heme oxygenase 1 suppresses endothelial cell apoptosis. J Exp Med 2000;192:1015-1026.

-25 Brouard S, Berberat PO, Tobiasch E, Seldon MP, Bach FH, Soares MP: Heme oxygenase1-derived carbon monoxide requires the activation of transcription factor NF- $\kappa \beta$ to protect endothelial cells from tumor necrosis factor- $\alpha$-mediated apoptosis. J Biol Chem 2002;277:17950-17961.

26 Zhang X, Shan P, Otterbein LE, Alam J, Flavell RA, Davis RJ, Choi AM, Lee PJ: Carbon monoxide inhibition of apoptosis during ischemia-reperfusion lung injury is dependent on the p38 mitogen-activated protein kinase pathway and involves caspase 3 . J Biol Chem 2003;278:1248-1258.

-27 Queiroga CS, Almeida AS, Alves PM, Brenner C, Vieira HL: Carbon monoxide prevents hepatic mitochondrial membrane permeabilization. BMC Cell Biol 2011;12:10.

28 Queiroga CS, Almeida AS, Martel C, Brenner C, Alves PM, Vieira HL: Glutathionylation of adenine nucleotide translocase induced by carbon monoxide prevents mitochondrial membrane permeabilization and apoptosis. J Biol Chem 2010;285:17077-17088.

29 Chung SW, Liu X, Macias AA, Baron RM, Perrella MA: Heme oxygenase-1-derived car- bon monoxide enhances the host defense response to microbial sepsis in mice. J Clin Invest 2008;118:239-247.

30 Otterbein LE, Bach FH, Alam J, Soares M, Tao Lu H, Wysk M, Davis RJ, Flavell RA, Choi AM: Carbon monoxide has anti-inflammatory effects involving the mitogen-activated protein kinase pathway. Nat Med 2000;6:422 428.

31 Sarady JK, Otterbein SL, Liu F, Otterbein LE, Choi AM: Carbon monoxide modulates endotoxin-induced production of granulocyte macrophage colony-stimulating factor in macrophages. Am J Respir Cell Mol Biol 2002; 27:739-745.

32 Reed JA, Whitsett JA: Granulocyte-macrophage colony-stimulating factor and pulmonary surfactant homeostasis. Proc Assoc Am Physicians 1998;110:321-332.

33 Parkes GC, Whelan K, Lindsay JO: Smoking in inflammatory bowel disease: impact on disease course and insights into the aetiology of its effect. J Crohns Colitis 2014;8:717-725.

34 Lunney PC, Leong RW: Review article: ulcerative colitis, smoking and nicotine therapy. Aliment Pharmacol Ther 2012;36:997-1008.

35 Otterbein LE, Mantell LL, Choi AM: Carbon monoxide provides protection against hyperoxic lung injury. Am J Physiol 1999;276:L688L694.

-36 Kaizu T, Nakao A, Tsung A, Toyokawa H, Sahai R, Geller DA, Murase N: Carbon monoxide inhalation ameliorates cold ischemia/reperfusion injury after rat liver transplantation. Surgery 2005;138:229-235.

- 37 Nakao A, Toyokawa H, Abe M, Kiyomoto T, Nakahira K, Choi AM, Nalesnik MA, Thomson AW, Murase N: Heart allograft protection with low-dose carbon monoxide inhalation: effects on inflammatory mediators and alloreactive T-cell responses. Transplantation 2006; 81:220-230.

38 Takagi T, Naito Y, Inoue M, Akagiri S, Mizushima K, Handa O, Kokura S, Ichikawa $\mathrm{H}$, Yoshikawa T: Inhalation of carbon monoxide ameliorates collagen-induced arthritis in mice and regulates the articular expression of IL- $1 \beta$ and MCP-1. Inflammation 2009;32: $83-88$.

39 Hegazi RA, Rao KN, Mayle A, Sepulveda AR, Otterbein LE, Plevy SE: Carbon monoxide ameliorates chronic murine colitis through a heme oxygenase 1-dependent pathway. J Exp Med 2005;202:1703-1713.

40 Sheikh SZ, Hegazi RA, Kobayashi T, Onyiah JC, Russo SM, Matsuoka K, Sepulveda AR, Li F, Otterbein LE, Plevy SE: An anti-inflammatory role for carbon monoxide and heme oxygenase-1 in chronic Th2-mediated murine colitis. J Immunol 2011;186:5506-5513.

41 Takagi T, Naito Y, Mizushima K, Akagiri S, Suzuki T, Hirata I, Omatsu T, Handa O, Kokura S, Ichikawa H, Yoshikawa T: Inhalation of carbon monoxide ameliorates TNBSinduced colitis in mice through the inhibition of TNF- $\alpha$ expression. Dig Dis Sci 2010;55: 2797-2804. 
42 Zuckerbraun BS, Otterbein LE, Boyle P, Jaffe R, Upperman J, Zamora R, Ford HR: Carbon monoxide protects against the development of experimental necrotizing enterocolitis. Am J Physiol Gastrointest Liver Physiol 2005; 289:G607-G613.

43 Motterlini R, Clark JE, Foresti R, Sarathchandra P, Mann BE, Green CJ: Carbon monoxide-releasing molecules: characterization of biochemical and vascular activities. Circ Res 2002;90:E17-E24.

44 Katada K, Bihari A, Mizuguchi S, Yoshida N, Yoshikawa T, Fraser DD, Potter RF, Cepinskas G: Carbon monoxide liberated from coreleasing molecule (CORM-2) attenuates ischemia/reperfusion (I/R)-induced inflammation in the small intestine. Inflammation 2010;33:92-100.
45 Fukuda W, Takagi T, Katada K, Mizushima K, Okayama T, Yoshida N, Kamada K, Uchiyama K, Ishikawa T, Handa O, Konishi H, Yagi N, Ichikawa H, Yoshikawa T, Cepinskas G, Naito Y, Itoh Y: Anti-inflammatory effects of carbon monoxide-releasing molecule on trinitrobenzene sulfonic acid-induced colitis in mice. Dig Dis Sci 2014;59:1142-1151.

46 Takagi T, Naito Y, Uchiyama K, Suzuki T, Hirata I, Mizushima K, Tsuboi H, Hayashi N, Handa O, Ishikawa T, Yagi N, Kokura S, Ichikawa $\mathrm{H}$, Yoshikawa T: Carbon monoxide liberated from carbon monoxide-releasing molecule exerts an anti-inflammatory effect on dextran sulfate sodium-induced colitis in mice. Dig Dis Sci 2011;56:1663-1671.

47 Joe Y, Uddin MJ, Zheng M, Kim HJ, Chen Y, Yoon NA, Cho GJ, Park JW, Chung HT: Tristetraprolin mediates anti-inflammatory effect of carbon monoxide against DSS-induced colitis. PLoS One 2014;9:e88776.

48 Uddin MJ, Jeong SO, Zheng M, Chen Y, Cho GJ, Chung HT, Joe Y: Carbon monoxide attenuates dextran sulfate sodium-induced colitis via inhibition of GSK-3 $\beta$ signaling. Oxid Med Cell Longev 2013;2013:210563.
9 Onyiah JC, Sheikh SZ, Maharshak N, Steinbach EC, Russo SM, Kobayashi T, Mackey LC, Hansen JJ, Moeser AJ, Rawls JF, Borst LB, Otterbein LE, Plevy SE: Carbon monoxide and heme oxygenase-1 prevent intestinal inflammation in mice by promoting bacterial clearance. Gastroenterology 2013;144:789-798.

50 Uchiyama K, Naito Y, Takagi T, Mizushima K, Hayashi N, Harusato A, Hirata I, Omatsu T, Handa O, Ishikawa T, Yagi N, Kokura S, Yoshikawa T: Carbon monoxide enhance colonic epithelial restitution via FGF15 derived from colonic myofibroblasts. Biochem Biophys Res Commun 2010;391:1122-1126.

51 Takagi T, Naito Y, Uchiyama K, Okuda T, Suzuki T, Tsuboi H, Mizushima K, Handa O, Yagi N, Ichikawa H, Yoshikawa T: Colonic insufflation with carbon monoxide gas inhibits the development of intestinal inflammation in rats. Med Gas Res 2012;2:23. 